\title{
LOOKING BACK TO THE FUTURE
}

Dear Reader,

has this happened to you? You come across an innovation in engine design and, at first glance, it seems very familiar. Your initial impression may well be right, because the latest developments are often based on fundamental concepts from the era of our fathers and grandfathers. In other words, they are very old ideas that in many cases needed or still need new technologies in order to be applied in an industrial context. There may be control and regulation problems, materials issues or challenges for processing and production. In addition, the time must be ripe for a new product, which means that it has to provide answers to current questions. Many innovations only develop their full potential together with other technologies. The individual ideas may have been around for a long time, but they can only bring the required benefits in combination with one another.

A constantly recurring theme in this context is the idea of water injection in combustion engines. A number of studies have been carried out into the use of additional water in the combustion chamber and the positive influence of water on soot and $\mathrm{NO}_{\mathrm{x}}$ emissions is well-known. However, a system has not yet been developed which is suitable for use in volume production. Promising results from a new research project into a diesel-water emulsion as a fuel for combustion engines are giving the activities in this area a new impetus. The study is being carried out by the Institute for Combustion Engines at RWTH Aachen University, the Institute for Physical Chemistry at the University of Cologne and the Institute for Automotive Engineering at Trier University of Applied Sciences on behalf of the Research Association for Combustion Engines. The difference in the approach on this project is that the researchers are not using a readymixed diesel-water emulsion. Instead the emulsion is mixed in the engine on the basis of the ignition map.

There are still serious problems with the diesel-water emulsion from a mechanical perspective. The researchers have identified extensive cavitation on the injection nozzles, which would significantly reduce the service life of the injectors. Further development work could probably solve this problem, together with that of the emulsion freezing in winter.

The cover story of this issue also concerns emission reductions, but in this case they are based on developments that are ready for volume production and can be implemented in the near future. I hope you enjoy reading this latest issue.

And don't forget to look back at the future every now and then.

Best regards,

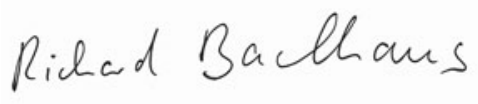

\section{RICHARD BACKHAUS,}

Vice-Editor in Chief

Wiesbaden, 11 April 2014

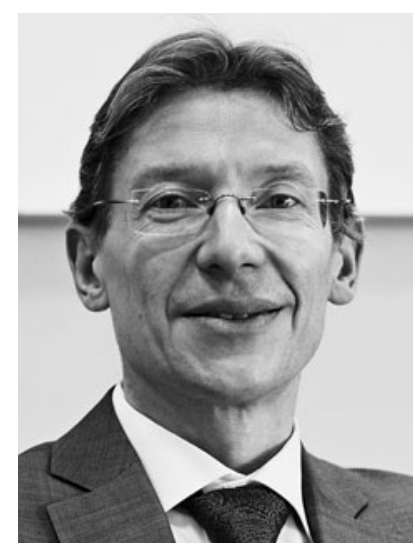

